\title{
Knockdown of vascular endothelial cell growth factor expression sensitizes U251 glioma cells to liposomal paclitaxel and radiation treatment in vitro
}

\author{
YANG YU, JIANGUO FENG, XIANGYUN ZONG, HONGJIAN YANG, DEHONG ZOU and XIANGMING HE \\ Department of Surgical Oncology, Zhejiang Cancer Hospital, Hangzhou, P.R. China
}

Received September 6, 2011; Accepted November 1, 2011

DOI: $10.3892 /$ etm.2011.379

\begin{abstract}
Glioblastoma is the most aggressive malignancy of the human brain, accounting for $40 \%$ of all primary malignant brain tumors. However, there is no effective treatment for this disease. This study was designed to develop anti-vascular endothelial growth factor (VEGF) as a novel adjuvant therapy for glioblastoma. A VEGF shRNA vector was constructed to silence VEGF expression in U251 glioma cells and these cells were treated with various concentrations of liposomal paclitaxel, 6 Gy radiation or liposomal paclitaxel plus radiation. The data demonstrated that the VEGF shRNA vector significantly knocked down VEGF expression, which synergistically sensitized U251 glioma cells to liposomal paclitaxel, radiation or liposomal paclitaxel plus radiation treatment in terms of cell viability, apoptosis, colony formation and morphological changes. Future studies are required to evaluate these effects in vivo.
\end{abstract}

\section{Introduction}

Glioblastoma is the most aggressive malignancy in the human brain, accounting for $40 \%$ of all primary malignant brain tumors. The survival rate is only 6-12 months following initial diagnosis (1-3). The majority of glioblastomas appear to be sporadic without any genetic predisposition; however, they occur more frequently in males. Surgery is currently the preferred approach to treating patients with glioblastoma; however, due to the lack of the clear boundaries between cancerous and normal tissues, it is difficult to completely remove the entire tumor lesion. The residual glioblastoma cells commonly spread along the ventricles following surgery. Radiotherapy is another choice for the treatment of glioblastoma, but the tolerance threshold of normal brain cells is lower than those of glioblastoma cells.

Correspondence to: Dr Xiangyun Zong, Department of Surgical Oncology, Zhejiang Provincial Cancer Hospital, 38 Guangji Road, Hangzhou 310022, P.R. China

E-mail: tigerzong2000@yahoo.com.cn

Key words: glioblastoma, vascular endothelial growth factor, gene therapy, liposomal paclitaxel, radiation, chemotherapy
Chemotherapy and immunotherapy are also routinely used to treat glioblastoma. The selection of these various treatments is dependent on the tumor location and stage, but in the majority of patients, a combined approach of surgery, radiation and chemotherapy will improve the survival rate. In recent years, novel approaches such as gene therapy or target therapy are emerging as new forms of adjuvant treatment for glioblastoma. Thus, these new approaches may provide useful insight into controlling glioblastoma formation.

To this end, the first use of targeted gene therapy for the treatment of glioblastoma was focused on targeting the epidermal growth factor receptor (EGFR) and platelet-derived growth factor receptor (PDGFR) (4-6). EGFR and PDGFR are usually overexpressed in glioblastoma cells and therefore the knockdown of their protein expression or inhibition of their gene activity could effectively control glioblastoma cell growth and improve the survival rate of the patients. Nevertheless, published data thus far have shown that these approaches have failed to achieve successful results (4-6), potentially due to drug resistance. Furthermore, certain other studies targeting the vascular endothelial growth factor (VEGF) have found some promising data (7). VEGF is a growth factor and is involved in vasculogenesis and angiogenesis. The overexpression of VEGF plays a significant role in cancer progression, since solid tumors cannot grow beyond a limited size without an adequate blood supply (8). Therefore, anti-VEGF therapy may become an important and effective approach in treating certain types of cancer. For example, a previous study using anti-VEGF therapy demonstrated the possibility of creating a treatment time window for combined radiotherapy and chemotherapy through antagonizing VEGF (9). Therefore, in the present study we investigated the effects of VEGF shRNA on the synergistic effects of combined chemotherapy and radiotherapy treatment of the U251 glioblastoma cell line in vitro. We evaluated VEGF shRNA in combination with liposomal paclitaxel for a potential combination therapy for the treatment of glioblastoma.

\section{Materials and methods}

Cell line and culture. The U251 glioma cell line was obtained from the Shanghai Cell Bank of the Chinese Academy of Sciences (Shanghai, China) and maintained in RPMI-1640 culture medium containing $10 \%$ fetal bovine serum and 
$1 \%$ penicillin-streptomycin solution (Hyclone, Logan, UT, USA) in a $5 \% \mathrm{CO}_{2}$ humidified incubator at $37^{\circ} \mathrm{C}$.

Reagents. Liposomal paclitaxel (30 mg/bottle) was obtained from the Institute of Pharmacology, Jiangsu Province, Nanjing Cisco Pharmaceutical Limited (Nanjing, China) and dissolved in saline into a $2 \mathrm{mg} / \mathrm{ml}$ stock solution prior to use.

VEGF shRNA oligonucleotides were custom-synthesized by Shanghai GeneChem Co. (Shanghai, China), the plasmid extraction kit was obtained from Invitrogen (Carlsbad, CA, USA), the plasmid transfection kit was from Promega (Madison, WI, USA), the VEGF-quantitative RT-PCR kit was from Da Hui Biological Agents (Foshan, China), tetrazolium blue (MTT) was from Huamei Biotechnology Ltd. (Luoyang, China), ethylenediaminetetraacetic acid (EDTA) and Giemsa stain were from Shanghai Sheng Gong Ltd. (Shanghai, China), dimethyl sulfoxide (DMSO) was from Shuang Liu Gong Mao Ltd. (Shanghai, China), and propidium iodide (PI) staining reagents were from BD company (San Jose, CA, USA).

Construction of VEGF shRNA and gene transfection. To knock down VEGF protein expression in the U251 glioma cell line, we first selected specific VEGF sequences for generating VEGF shRNA constructs. We searched GenBank and chose the VEGF sequence of 5'-GGAGTACCCTGATGAGATC-3' as the target for PCR amplification. We then annealed the hairpin-designed sense and antisense VEGF shRNA oligonucleotides together to form the double-strand DNA for the construction of the VEGF shRNA vector. A total of $5 \mu \mathrm{l}$ each of sense and antisense single-stranded oligonucleotides, $20 \mu \mathrm{l}$ $5 \mathrm{X}$ buffer and $70 \mu 1 \mathrm{ddH}_{2} \mathrm{O}$ were mixed and incubated at $90^{\circ} \mathrm{C}$ for $4 \mathrm{~min}$ and $70^{\circ} \mathrm{C}$ for $10 \mathrm{~min}$ and then slowly cooled down to room temperature and diluted into $100 \mathrm{ng} / \mu \mathrm{l}$. The newly-annealed double-strand DNA oligonucleotides were ligated to the previously linearized pGCsiU6/Neo/GFP vector (Shanghai GeneChem Co.) using T4 ligase (Fermentas China Co. Ltd., Shenzhen, China), and then amplified and sequence-confirmed prior to use. For gene transfection, we mixed $6 \mu 1$ of the liposome with plasmid DNA at a ratio of 3:1 and added this into $2.5 \mathrm{ml}$ serum free medium to transfer VEGF shRNA into the glioma cells. One hour later, the growth medium was refreshed with regular RPMI-1640 and the cells were cultured for up to $72 \mathrm{~h}$. Cell growth and gene expression were then measured.

Quantitative reverse transcription-polymerase chain reaction (qRT-PCR). qRT-PCR was used to detect gene expression. Briefly, following gene transfection, the VEGF mRNA levels in U251 cells were assessed using qRT-PCR. Total RNA and mRNA were extracted and isolated according to a previously described protocol (10). mRNA was then subjected to reverse transcription using random primers with M-MLV reverse transcriptase (Promega) into cDNA. VEGF primers used for qRT-PCR were 5'-TGCCAGCAACACTACCAC-3' (upstream) and 5'-GAGTCATCTCCAGCATCC-3' (downstream). qRT-PCR was performed using a kit from Da Hui Biological agents, which also contained a standard control for copy numbers (i.e., $1 \times 10^{9}$ diluted into $4 \times 10^{4}$ to $4 \times 10^{7}$ ). SYBR-Green was used to detect the yield of these copy numbers. PCR was initiated with a denaturation of $5 \mathrm{~min}$ at $95^{\circ} \mathrm{C}$, followed by
35 cycles of $95^{\circ} \mathrm{C}$ for $30 \mathrm{sec}, 59^{\circ} \mathrm{C}$ for $35 \mathrm{sec}$, and a final elongation of $72^{\circ} \mathrm{C}$ for 10 min using an Applied Biosystems PE7500 Sequence Detection System (Applied Biosystems, Foster City, CA, USA). Gene expression was normalized and controls were calculated from the standard curve.

Flow cytometry and MTT colorimetric assay. U251 cells in logarithmic growth phases were suspended and seeded at a density of 10,000 cells/well for culture for $24,48,72$ and $96 \mathrm{~h}$, with or without drug treatment, radiation, or gene transfection prior to collection into centrifuge tubes for supernatant isolation. The isolated cells were then processed for PI staining prior to flow cytometry to examine the cell cycle and rates of apoptosis.

For the MTT assay, the U251 cells were treated with liposomal paclitaxel at a concentration of $0.512,2.56,12.8$ and $64 \mu \mathrm{g} / \mathrm{ml}$, and $0.32,1.6,8,40,200$ or $1,000 \mathrm{mg} / \mathrm{ml}$ for $48 \mathrm{~h}$ with or without gene transfection and radiation treatment. A total of $5 \mu \mathrm{g} / \mathrm{ml}$ of MTT was then added to the cultures for an additional $4 \mathrm{~h}$ and the reaction was stopped by adding $150 \mu \mathrm{l}$ DMSO. The optical density (OD) of the cell cultures was then read using an Agilent 8453 spectrophotometer (Agilent Technologies, Foster City, CA, USA) with an absorption wavelength of $550 \mathrm{~nm}$. The inhibition rate $=$ [blank control group $\mathrm{OD}_{550}$ - (experimental group $\mathrm{OD}_{550}$ - background control group $\left.\left.\mathrm{OD}_{550}\right)\right] /$ control group $\mathrm{OD}_{550} \times 100 \%$.

Colony formation assay, cloning efficiency test and morphological analysis. To test the effects of VEGF shRNA on the modulation of sensitivity of U251 cells to liposomal paclitaxel and/or radiation treatment, U251 cells in a logarithmic growth phase were cultured in soft agar and treated with liposomal paclitaxel at a concentration of $64 \mathrm{mg} / \mathrm{ml}$ and/or a 6 Gy dose of radiation for $48 \mathrm{~h}$ in 8 groups, i.e., control group (A group), control + radiation (B), control + paclitaxel (C), control + paclitaxel + radiation (D), VEGF shRNA-transfected cells (E), VEGF shRNA-transfected cells + radiotherapy (F), VEGF shRNA-transfected cells + paclitaxel (G), VEGF shRNAtransfected cells + paclitaxel + radiation $(\mathrm{H})$. The medium was then refreshed and the cells were cultured under normal conditions for an additional 10 days prior to fixation and Giemsa staining. The number of clones was counted in each well (50 cells or more were considered a colony) and 3 wells were used for each treatment. For total colony counts for each treatment group, the average of the total of the 3 wells was used for calculation. Changing rates for colony formation and colony formation inhibition rates were calculated as follows: colony formation rate $(\%)=$ colony/seeded cells $\times 100 \%$; colony formation inhibition rate $(\%)=($ control colony number - plus drug group colony)/control group colony x $100 \%$.

A similar treatment of 8 groups of cells was plated on a monolayer for morphological analyses. These cells were further cultured under normal conditions for 24 or $48 \mathrm{~h}$ prior to being observed under an inverted microscope.

Statistical analyses. The experimental data are summarized as the means \pm standard deviation (SD). Under the condition of homogeneity of variance, the variance F-test was used to compare the means among all the groups, and $\mathrm{q}$ for comparisons between any two tests (Newman-Keuls method). 
Table I. Knockdown of VEGF mRNA expression by using VEGF shRNA.

\begin{tabular}{|c|c|c|c|c|}
\hline & \multicolumn{4}{|c|}{ VEGF copy number pre- and post-transfection } \\
\hline & Control & $24 \mathrm{~h}$ & $48 \mathrm{~h}$ & $72 \mathrm{~h}$ \\
\hline 1 & 4723.90 & 316.72 & 417.40 & 351.48 \\
\hline 2 & 12361.20 & 451.65 & 746.38 & 750.98 \\
\hline 3 & 46511.90 & 1817.73 & 1054.22 & 928.61 \\
\hline 4 & 14063.20 & 357.57 & 852.76 & 440.27 \\
\hline 5 & 10160.60 & 379.97 & 402.65 & 501.72 \\
\hline Mean \pm SD & $17564.16 \pm 7406.03$ & $664.73 \pm 289.08$ & $694.68 \pm 126.31$ & $594.61 \pm 106.67$ \\
\hline P-value & \multicolumn{4}{|c|}{$0.039(\mathrm{~F}=6.074)$} \\
\hline
\end{tabular}

VEGF, vascular endothelial growth factor; SD, standard deviation.

Table II. Effect of VEGF knockdown on modulation of U251 cell sensitivity to paclitaxel treatment.

\begin{tabular}{|c|c|c|c|c|}
\hline \multirow[t]{2}{*}{ Drug concentration } & \multicolumn{2}{|c|}{$\mathrm{OD}_{550}(\overline{\mathrm{x}} \pm \mathrm{SD})$} & \multicolumn{2}{|c|}{ Inhibition rate $(\%)$} \\
\hline & $\begin{array}{c}\text { Control } \\
\text { transfection }\end{array}$ & $\begin{array}{l}\text { VEGF shRNA } \\
\text { transfection }\end{array}$ & $\begin{array}{c}\text { Control } \\
\text { transfection }\end{array}$ & $\begin{array}{c}\text { VEGF shRNA } \\
\text { transfection }\end{array}$ \\
\hline $0.000512 \mathrm{mg} / \mathrm{ml}$ & $1.65 \pm 0.11$ & $1.23 \pm 0.12$ & 2.17 & 24.46 \\
\hline $0.00256 \mathrm{mg} / \mathrm{ml}$ & $1.55 \pm 0.10$ & $1.10 \pm 0.13$ & 7.90 & 32.18 \\
\hline $0.0128 \mathrm{mg} / \mathrm{ml}$ & $1.41 \pm 0.15$ & $0.92 \pm 0.11$ & 16.50 & 43.18 \\
\hline $0.064 \mathrm{mg} / \mathrm{ml}$ & $1.29 \pm 0.12$ & $0.65 \pm 0.11$ & 23.80 & 60.13 \\
\hline $0.32 \mathrm{mg} / \mathrm{ml}$ & $1.21 \pm 0.15$ & $0.54 \pm 0.16$ & 28.20 & 66.61 \\
\hline $1.6 \mathrm{mg} / \mathrm{ml}$ & $1.10 \pm 0.17$ & $0.40 \pm 0.10$ & 34.57 & 75.10 \\
\hline $8 \mathrm{mg} / \mathrm{ml}$ & $0.98 \pm 0.26$ & $0.22 \pm 0.12$ & 41.96 & 86.19 \\
\hline $40 \mathrm{mg} / \mathrm{ml}$ & $0.81 \pm 0.09$ & $0.15 \pm 0.10$ & 52.28 & 90.62 \\
\hline $200 \mathrm{mg} / \mathrm{ml}$ & $0.62 \pm 0.14$ & $0.09 \pm 0.05$ & 63.14 & 94.32 \\
\hline Control & $1.69 \pm 0.10$ & $1.62 \pm 0.15$ & \multicolumn{2}{|c|}{$\mathrm{P}=0.009$} \\
\hline
\end{tabular}

VEGF, vascular endothelial growth factor; SD, standard deviation.

Non-parametric test methods were used for clone counting. SPSS 11.0 software (SPSS, Chicago, IL, USA) was used for all statistical analyses and $\mathrm{P}<0.05$ was considered to indicate a statistically significant difference.

\section{Results}

Knockdown of VEGF mRNA expression using VEGF shRNA. In this study, we first knocked down VEGF mRNA expression in U251 glioma cells using a VEGF shRNA vector. Compared to the control transfection, VEGF shRNA significantly inhibited VEGF mRNA levels $(\mathrm{P}<0.001)$ (Table I).

Effects of VEGF knockdown on changes in the cell cycle and apoptotic rate. The effects of VEGF knockdown on changes in the cell cycle and apoptotic rate were determined in U251 cells. The flow cytometric data showed that the control cells and VEGF shRNA-transfected cells exhibited G0-G1 arrest and a reduced number of cells in the $\mathrm{G} 2$ and $\mathrm{M}$ phases, but did not show a decrease in the proportion of $S$ phase cells within the first 48 h. By contrast, after 48 h, VEGF shRNA-transfected cells showed apoptosis in a time-dependent manner, i.e., the apoptotic rate of VEGF shRNA-transfected cells was 1.5, 2.7 and $4.3 \%$ at 24,48 and $72 \mathrm{~h}$, respectively, whereas that of the controls was $0.39,0.55$ and $0.30 \%$, respectively $(\mathrm{F}=8.832$, $\mathrm{P}=0.041$ ).

Paclitaxel inhibition of U251 cell viability. U251 cells were treated with various concentrations of paclitaxel and we found that paclitaxel reduced $\mathrm{U} 251$ cell viability, with an $\mathrm{IC}_{50}$ of $28.1 \mu \mathrm{g} / \mathrm{ml}$ following $48 \mathrm{~h}$ of treatment. However, VEGF knockdown significantly sensitized U251 cells to paclitaxel treatment $\left(\mathrm{IC}_{50}\right.$ of $28.1 \mu \mathrm{g} / \mathrm{ml}$ to an $\mathrm{IC}_{50}$ of $0.02 \mu \mathrm{g} / \mathrm{ml}$ in the VEGF-transfected cells). These data suggest that the knockdown of VEGF significantly synergized the effect of paclitaxel in U251 glioma cells $(\mathrm{F}=8.533, \mathrm{P}=0.009)$. The effects of liposomal paclitaxel on U251 cell proliferation are summarized in Table II and Fig. 1. 


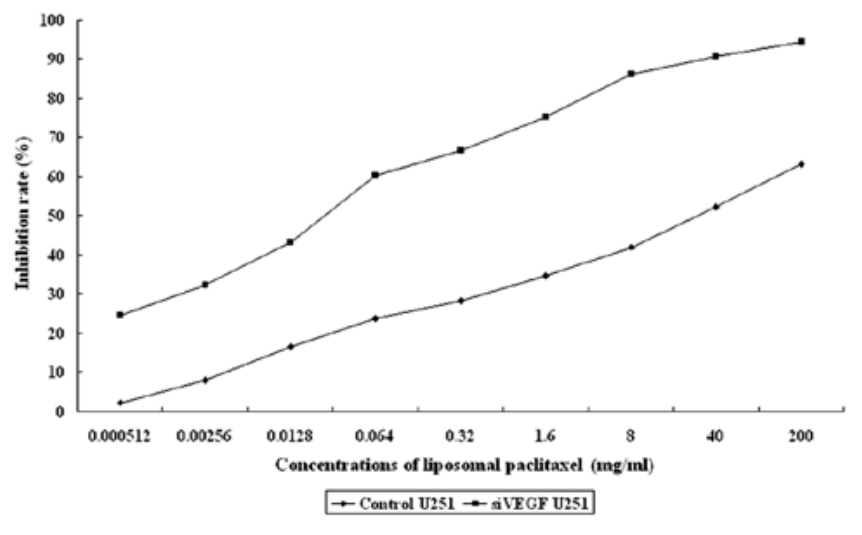

Figure 1. The effect of VEGF knockdown on modulation of U251 cell sensitivity to paclitaxel treatment. U251 glioma cells were grown and transfected with the control or VEGF shRNA vector for $24 \mathrm{~h}$ and then treated with or without various concentrations of liposomal paclitaxel for $48 \mathrm{~h}$. An MTT assay was performed to detect the changes in cell viability. The data were summarized as the percentage of inhibition. The $\mathrm{IC}_{50}$ determined at $48 \mathrm{~h}$ after liposomal paclitaxel treatment was $28.1 \mathrm{mg} / \mathrm{ml}$, while it was $0.02 \mathrm{mg} / \mathrm{ml}$ with VEGF shRNA transfection. There was a statistical significance among the different doses of paclitaxel treatment prior to and following gene transfection $(\mathrm{F}=8.533, \mathrm{P}=0.009)$. VEGF, vascular endothelial growth factor.

Reduction of U251 cell colony-formation with combined treatment with VEGF knockdown. We also tested the combination of VEGF shRNA, paclitaxel and radiation on changes in colony formation of U251 cells. We utilized a dose of paclitaxel ( $2.56 \mathrm{mg} / \mathrm{ml}$ of liposomal paclitaxel) to treat U251 glioma cells with or without VEGF shRNA transfection for the colony formation assay. These data showed that colony forming cells in the control group were (group A), 23.83\%; control + radiation (B), 17.0\%; control + paclitaxel (C), 18.23\%; control + paclitaxel + radiation (D), 12.67\%; VEGF shRNA-transfected cells (E), 17.57\%; radiation + VEGF shRNA-transfection (F), 9.67\%; VEGF shRNA-transfection + paclitaxel (G), 13.4\%; VEGF shRNA-transfection + paclitaxel + radiation (H), 6.33\% (Fig. 2). These data demonstrate that VEGF knockdown significantly sensitizes U251 cells to paclitaxel and/or radiation treatment. For example, colony formation in the control transfection group was $17.93 \pm 2.30 \%$, while colony formation in VEGF shRNAtransfected cells was $11.74 \pm 1.58 \%(\mathrm{P}=0.049)$. The groups with drug treatment alone and radiotherapy alone showed no significant difference $(\mathrm{P}>0.05)$. Following VEGF knockdown, colony formation in paclitaxel and radiation-treated U251 cells was significantly reduced (from 17.57 to $6.33 \%, \mathrm{P}=0.001$ ).

The changes in cell morphology following treatment. In addition, we also observed changes in cell morphology following these treatments. We found that cells in the experimental groups showed some morphological changes when compared to the control groups, and the transfected group showed more severe cellular morphological changes than non-transfected cells by microscopy (Fig. 3).

\section{Discussion}

To date, it is an enormous challenge to manage and cure glioblastoma in neuro-oncological clinics, although surgery and chemo- and radiation therapy are now available to treat this

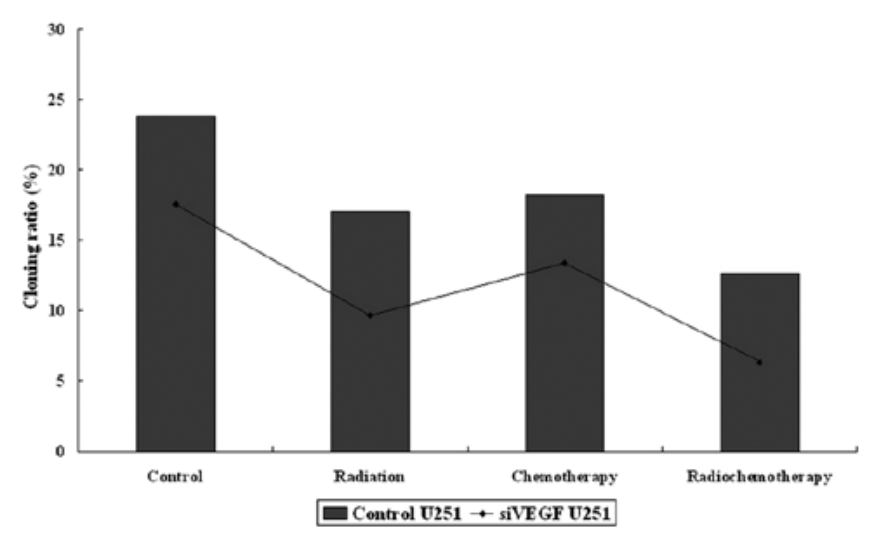

Figure 2. The U251 cells were grown and transfected with control or VEGF shRNA vectors and then treated with or without paclitaxel and radiation for $48 \mathrm{~h}$ and grown for an additional 10 days. The dose of liposomal paclitaxel was $2.56 \mathrm{~g} / \mathrm{ml}$ and the radiation dose was $6 \mathrm{~Gy}$. VEGF, vascular endothelial growth factor.

A
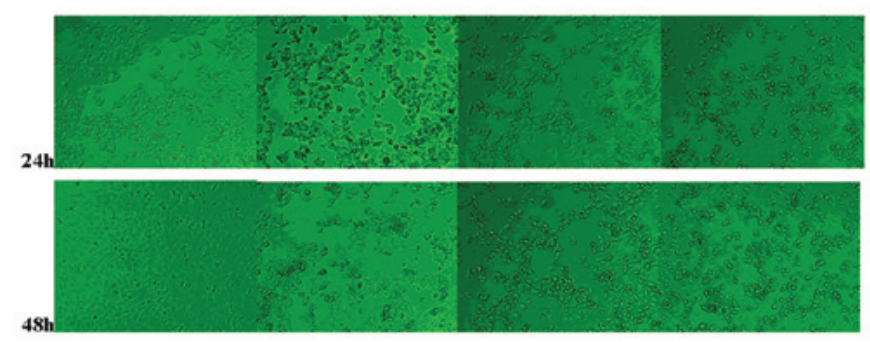

$\mathbf{E}$
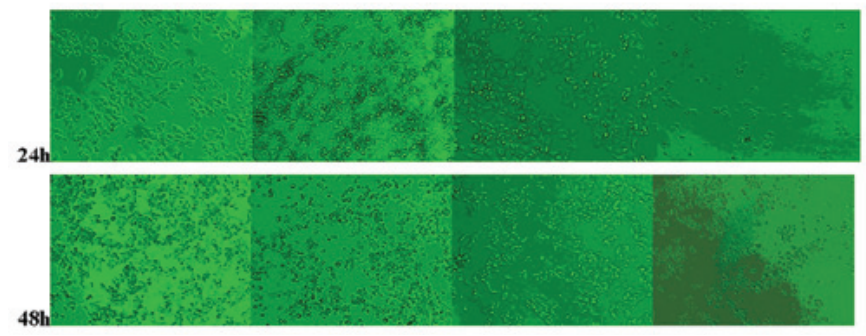

Figure 3. Changed cell morphology of U251 cells following VEGF knockdown plus paclitaxel and radiation treatment. The U251 cells were grown and transfected with control or VEGF shRNA vector and then treated with or without paclitaxel and radiation for $48 \mathrm{~h}$ and grown for an additional 10 days. Cell morphology was reviewed under the microscope and images were captured at x100 magnification. The dose of liposomal paclitaxel was $2.56 \mathrm{~g} / \mathrm{ml}$ and the radiation dose was $6 \mathrm{~Gy}$. (A) control group, (B) control + radiation, (C) control + paclitaxel, (D) control + paclitaxel + radiation, (E) VEGF shRNA-transfected cells, (F) VEGF shRNA-transfected cells + radiotherapy, (G) VEGF shRNA-transfected cells + paclitaxel, (H) VEGF shRNA-transfected cells + paclitaxel + radiation. VEGF, vascular endothelial growth factor.

deadly disease $(11,12)$. This is due to the fact that the majority of patients still die within 6-12 months of diagnosis. In the current study, we explored the knockdown of VEGF expression as a novel adjuvant treatment for glioblastoma. We first constructed a VEGF shRNA expression vector to silence VEGF expression in a glioma cell line. We found that compared to the vector-only control cells, the VEGF shRNA-transfected glioma cells were much more sensitive to various doses of liposomal paclitaxel, 6 Gy radiation or liposomal paclitaxel plus radiation treatment. 
The tumor cells underwent apoptosis, decreased colony formation in soft agar plates and reduced cell viability following VEGF knockdown and the combined chemo- and radiation treatment. Our study clearly demonstrates that the silencing of VEGF expression synergistically sensitizes U251 glioma cells to liposomal paclitaxel, radiation and liposomal paclitaxel plus radiation treatment. However, further studies are required to evaluate the clinical efficacy of this treatment.

VEGF is the main angiogenesis regulator that plays a significant role in tumor development and progression. In the present study, we showed that VEGF mRNA expression was decreased by more than $60 \%$ following VEGF shRNA vector transfection into U251 glioma cells. Phenotypically, VEGF shRNA delayed tumor cell cycles and increased apoptosis in U251 cells compared to the control cells, which was supported by a previous study in experimental mouse brain tumors (13). However, our current study showed a lesser degree of apoptotic induction by VEGF shRNA than that of the previous report (13). However, we did find the synergistic effects of VEGF knockdown with radiation therapy in tumor cells, as has been suggested in previous studies (14,15). For example, Winkler et al (16) showed that antiVEGF receptor antibodies could open a time window with high oxygen levels in tumor cells, during which time the radiation therapy could achieve the best synergistic effect. Another study by Hovinga et al (17) showed that the increase of VEGF in tumor cells correlated with radiation therapy, and could reflect the inborn response of self-protection, which would protect tumor cells from apoptosis and induce new blood vessels. Our current data indicate that VEGF shRNA increases the effect of radiation in a glioma cell line in vitro. Furthermore, we also found that VEGF shRNA enhances the efficiency of chemotherapy in U251 cells. Treatment of glioma cells with paclitaxel and radiotherapy alone showed similar results with limited effects, whereas the addition of VEGF shRNA transfection showed the best effects on glioma cells when compared to other double or single treatments, suggesting that VEGF shRNA was able to sensitize U251 cells to radiotherapy and chemotherapy (18), possibly via different mechanisms.

Furthermore, current chemotherapy treatment of glioma lacks efficacy, which could be due to the blood-brain barrier and less successful drug delivery methods (19). In the current study, we tested the liposome-based drug delivery, which could provide a new avenue for treatment. This is due to the fact that liposome-based drug delivery is capable of enhancing permeation and retention rates with nano-sized drug carriers (20). Liposomes could more easily cross epithelial cells within the tumor from the blood circulation $(21,22)$, and cross the blood-brain barrier through the enhanced permeability by VEGF shRNA transfection (23). The liposome-based drug delivery may also increase efficiency of the convection-enhanced delivery system (24) to cross the blood-brain barrier. Indeed, the results from our current study showed that the $\mathrm{IC}_{50}$ of liposomal paclitaxel decreased from 28.1 to $0.02 \mathrm{mg} / \mathrm{ml}$ following VEGF shRNA transfection, suggesting that the liposomal paclitaxel plus VEGF shRNA transfection could be an effective adjuvant therapy, particularly for glioblastoma and other types of cancer that are sensitive to VEGF-targeted gene therapy.

In conclusion, the data from our current study present a novel adjuvant treatment regime for glioblastoma with the combination of chemo- and radiation therapy following
VEGF shRNA transfection. Our data demonstrate that the knockdown of VEGF expression in U251 glioma cells inhibits tumor cell viability and promotes tumor cell apoptosis, but significantly increases the sensitivity of U251 cells to radiotherapy and chemotherapy. Furthermore, liposomal paclitaxel, as a novel drug delivery method, could enhance drug delivery in vivo, although the VEGF gene interference and the practical application of liposomal paclitaxel remains to be examined and explored in future studies.

\section{Acknowledgements}

We thank Medjaden Bioscience Limited, Hong Kong, China, for editing the manuscript.

\section{References}

1. Jemal A, Murray T, Ward E, et al: Cancer statistics. CA Cancer J Clin 55: 10-30, 2005.

2. Behin A, Hoang-Xuan K, Carpentier AF, et al: Primary brain tumours in adults. Lancet 361: 323-331, 2003.

3. Meyer MA: Malignant gliomas in adults. N Engl J Med 359: 1850,2007

4. Furnari FB, Fenton T, Bachoo RM, et al: Malignant astrocytic glioma: genetics, biology, and paths to treatment. Genes Dev 21: 2683-2710, 2007.

5. De Witt Hamer PC: Small molecule kinase inhibitors in glioblastoma: a systematic review of clinical studies. Neuro Oncol 12: 304-316, 2010.

6. Lo HW: EGFR-targeted therapy in malignant glioma: novel aspects and mechanisms of drug resistance. Curr Mol Pharmacol 3: 37-52, 2010.

7. Machein M and de Miguel LS: Angiogenesis in gliomas. Recent Results Cancer Res 171: 193-215, 2009.

8. Jain RK, di Tomaso E, Duda DG, et al: Angiogenesis in brain tumours. Nat Rev Neurosci 8: 610-622, 2007.

9. Lin MI and Sessa WC: Antiangiogenic therapy: creating a unique 'window' of opportunity. Cancer Cell 6: 529-531, 2004.

10. Said HM, Hagemann C, Staab A, et al: Expression patterns of the hypoxia-related genes osteopontin, CA9, erythropoietin, VEGF and HIF-1alpha in human glioma in vitro and in vivo. Radiother Oncol 83: 398-405, 2007.

11. Damiano V, Melisi D, Bianco C, et al: Cooperative antitumor effect of multitargeted kinase inhibitor ZD6474 and ionizing radiation in glioblastoma. Clin Cancer Res 11: 5639-5644, 2005.

12. Abdollahi A, Lipson KE, Sckell A, et al: Combined therapy with direct and indirect angiogenesis inhibition results in enhanced antiangiogenic and antitumor effects. Cancer Res 63: 8890-8898, 2003.

13. Kamoun WS, Ley CD, Farrar CT, et al: Edema control by cediranib, a vascular endothelial growth factor receptor-targeted kinase inhibitor, prolongs survival despite persistent brain tumor growth in mice. J Clin Oncol 27: 2542-2552, 2009.

14. Tabatabai G, Frank B, Wick A, et al: Synergistic antiglioma activity of radiotherapy and enzastaurin. Ann Neurol 61: 153-161, 2007.

15. Wachsberger PR, Burd R, Cardi C, et al: VEGF trap in combination with radiotherapy improves tumor control in $\mathrm{u} 87$ glioblastoma. Int J Radiat Oncol Biol Phys 67: 1526-1537, 2007.

16. Winkler F, Kozin SV, Tong RT, et al: Kinetics of vascular normalization by VEGFR2 blockade governs brain tumor response to radiation: role of oxygenation, angiopoietin-1, and matrix metalloproteinases. Cancer Cell 6: 553-563, 2004.

17. Hovinga KE, Stalpers LJ, van Bree C, et al: Radiation-enhanced vascular endothelial growth factor (VEGF) secretion in glioblastoma multiforme cell lines - a clue to radioresistance? J Neurooncol 74: 99-103, 2005.

18. Fountzilas G, Karkavelas G, Kalogera-Fountzila A, et al: Post-operative combined radiation and chemotherapy with temozolomide and irinotecan in patients with high-grade astrocytic tumors. A phase II study with biomarker evaluation. Anticancer Res 26: 4675-4686, 2006.

19. Kesari S, Schiff D, Henson JW, et al: Phase II study of temozolomide, thalidomide, and celecoxib for newly diagnosed glioblastoma in adults. Neuro Oncol 10: 300-308, 2008. 
20. Matsumura Y and Maeda A: A new concept for macromolecular therapies in cancer chemotherapy: mechanisms of tumortropic accumulation of proteins and the antitumor agents smancs. Cancer Res 46: 6387-6392, 1986.

21. Harrington KJ, Mohammadtaghi S, Uster PS, et al: Effective targeting of solid tumors in patients with locally advanced cancers by radiolabeled pegylated liposomes. Clin Cancer Res 7: 243-254, 2001.

22. Noble CO, Kirpotin DB, Hayes ME, et al: Development of ligand targeted liposomes for cancer therapy. Expert Opin Ther Targets 8: 335-353, 2004.
23. Aoki H, Kakinuma K, Morita K, et al: Therapeutic efficacy of targeting chemotherapy using local hyperthermia and thermosensitive liposome: evaluation of drug distribution in a rat glioma model. Int J Hypertherm 20: 595-605, 2005.

24. Mamot C, Nguyen JB, Pourdehnad M, et al: Extensive distribution of liposomes in rodent brains and brain tumors following convection-enhanced delivery. J Neurooncol 68: 1-9, 2004. 